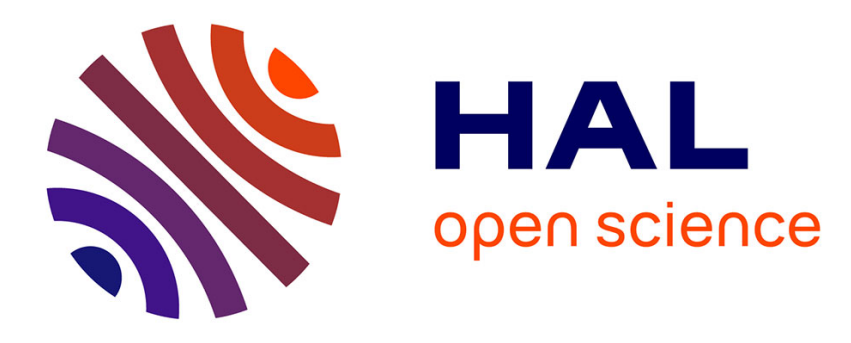

\title{
Surface Tension Drives the Orientation of Crystals at the Air-Water Interface
}

Nicolas R. Chevalier, Patrick Guenoun

\section{To cite this version:}

Nicolas R. Chevalier, Patrick Guenoun. Surface Tension Drives the Orientation of Crystals at the Air-Water Interface. Journal of Physical Chemistry Letters, 2016, 7, pp.2809-2813. 10.1021/acs.jpclett.6b01312 . cea-01345285

\section{HAL Id: cea-01345285 https://hal-cea.archives-ouvertes.fr/cea-01345285}

Submitted on 13 Jul 2016

HAL is a multi-disciplinary open access archive for the deposit and dissemination of scientific research documents, whether they are published or not. The documents may come from teaching and research institutions in France or abroad, or from public or private research centers.
L'archive ouverte pluridisciplinaire HAL, est destinée au dépôt et à la diffusion de documents scientifiques de niveau recherche, publiés ou non, émanant des établissements d'enseignement et de recherche français ou étrangers, des laboratoires publics ou privés. 


\title{
Surface Tension Drives the Orientation of Crystals at the Air-Water Interface
}

\author{
Nicolas R. Chevalier* ${ }^{\dagger} \dagger$ and Patrick Guenoun \\ LIONS, NIMBE, CEA, CNRS, Université Paris-Saclay, CEA Saclay 91191 Gif sur Yvette Cedex, France \\ Supporting Information
}

ABSTRACT: The fabrication of oriented crystalline thin films is essential for a range of applications ranging from semiconductors to optical components, sensors, and catalysis. Here we show by depositing micrometric crystal particles on a liquid interface from an aerosol phase that the surface tension of the liquid alone can drive the crystallographic orientation of initially randomly oriented particles. The X-ray diffraction patterns of the particles at the interface are identical to those of a monocrystalline sample cleaved along the $\{104\}\left(\mathrm{CaCO}_{3}\right)$ or $\{111\}\left(\mathrm{CaF}_{2}\right)$ face. We show how this orientation effect can be used to produce thin coatings of oriented crystals on a solid substrate. These results also have important implications for our understanding of heterogeneous crystal growth beneath amphiphile monolayers and for $2 \mathrm{D}$ self-assembly processes at the air-liquid interface.

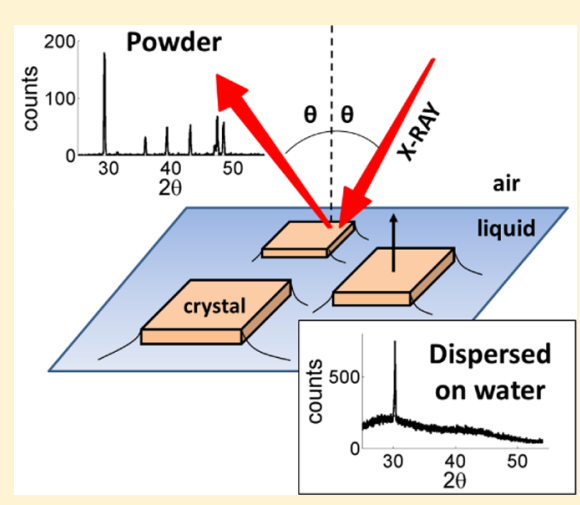

$\mathrm{T}$ he first crystals to grow from a supersaturated aqueous solution often nucleate at the air-water interface. This can happen for a variety of reasons. When crystallization is induced by cooling of a hot, saturated salt solution, for example, faster cooling at the air-water interface makes the supersaturation highest at this location. $\mathrm{CaCO}_{3}$ nucleation from hard water occurs first at the interface because gaseous $\mathrm{CO}_{2}$ resulting from the reaction $\mathrm{Ca}^{2+}+2 \mathrm{HCO}_{3}^{-} \rightarrow \mathrm{CaCO}_{3}+\mathrm{CO}_{2}+\mathrm{H}_{2} \mathrm{O}$ escapes from the air-water interface, driving the formation of $\mathrm{CaCO}_{3}$ rafts. ${ }^{1}$ Heterogeneous nucleation at the air-water interface can also be thermodynamically favored because it provides a lower nucleation barrier compared with bulk nucleation. In particular, amphiphilic molecules deposited at the air-water interface can dramatically reduce the nucleation barrier and provide a $2 \mathrm{D}$ template for $3 \mathrm{D}$ crystal growth from solution. ${ }^{2,3}$ Several investigators have relied on this system to provide insights into fundamental mechanisms of heterogeneous nucleation such as the epitaxial growth of ice crystals below alcohol monolayers, ${ }^{4}$ single-crystal $\mathrm{ZnO}$ nanosheet growth at the air-water interface, ${ }^{5}$ organic-inorganic epitaxial growth of calcite below sulfate monolayers, ${ }^{6} \mathrm{CaCO}_{3}$ polymorph control, ${ }^{7}$ recognition ${ }^{8}$ by peptide monolayers, and templatecrystal adaptability. ${ }^{9}$ These findings have fundamental implications for our understanding of the complex heterogeneous crystal nucleation phenomena occurring during biomineralization. ${ }^{10}$ They hold great promise to better control or prevent crystal formation in situations where nucleation should by all means be avoided (ice nucleation on airplane sensors, $\mathrm{CaCO}_{3}$ scale formation in hardwater pipes ${ }^{11}$ ). Last but not least, the fabrication of oriented mineral coatings and thin oriented crystals films ${ }^{12}$ is essential for a wide range of applications ranging from semiconductors to sensors, optical components, paper manufacturing, paint, cosmetics, and skin care.

The orientation of 3D crystals growing beneath 2D amphiphile monolayers is usually ascribed to epitaxial or headgroup stereochemical matching mechanisms ${ }^{13,14}$ between the $3 \mathrm{D}$ crystal and the $2 \mathrm{D}$ template. We were interested in knowing whether surface tension forces could play a role in orienting the crystals at the interface as well, as suggested by DiMasi et al. ${ }^{15}$ We started from a configuration where the crystallites were randomly oriented by forming a cloud (aerosol) of $\mathrm{CaCO}_{3}$ particles. This cloud of calcite crystals (average size $1-10 \mu \mathrm{m}$ ) was formed by collecting a small quantity of calcite powder with a brush and by shaking it above a Petri dish filled with liquid (Figure 1a). The crystal film at the interface was at first homogeneous. After 1 day, the particles at the air-water interface had aggregated to form a fractal-like network (Figure 1b). The formation of these networks has been studied in detail by Nakayama et al. ${ }^{16}$

We then compared the $\theta-2 \theta \mathrm{X}$-ray diffraction pattern of the floating calcite crystal layers with the usual powder pattern from a thick pellet of dry powder (obtained by compressing the powder in a $\sim 5 \mathrm{~mm}$ high cylindrical hole).

The relative X-ray diffraction intensities (Figure 2a) of the dry powder were consistent with those reported in the Mincryst powder diffraction database. ${ }^{17}$ For the floating calcite crystal layer, all peaks but 104 almost completely vanished from the Xray diffraction spectrum (Figure $2 \mathrm{~b}$ ). This indicates that the crystals at the air-water interface have their $\{104\}$ face oriented parallel to the air-water interface. A similar diffraction pattern

Received: June 14, 2016

Accepted: July 8, 2016 


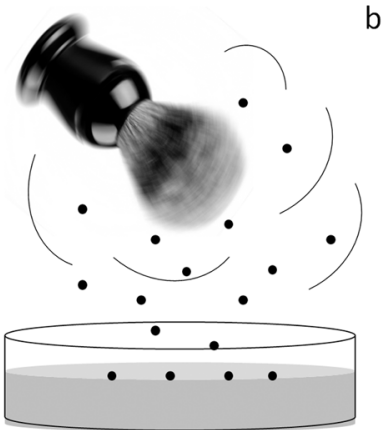

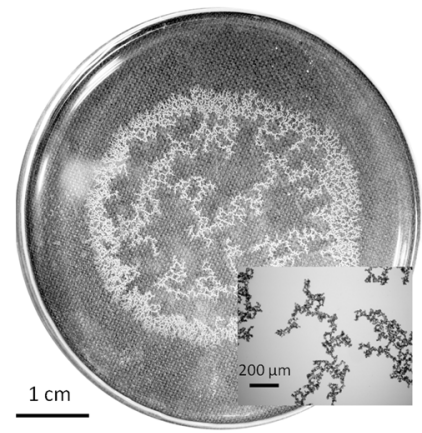

Figure 1. (a) Scheme of the method applied to form thin crystalline films at the air-liquid interface. The photograph of the shaving brush is reproduced here with kind permission of the company Alepia. (b) Top view of $\mathrm{CaCO}_{3}$ crystals on water 1 day after they were deposited at the interface. The surface area occupied by crystals after powdering is $\sim 10 \%$. Inset: fractal aggregate detail.
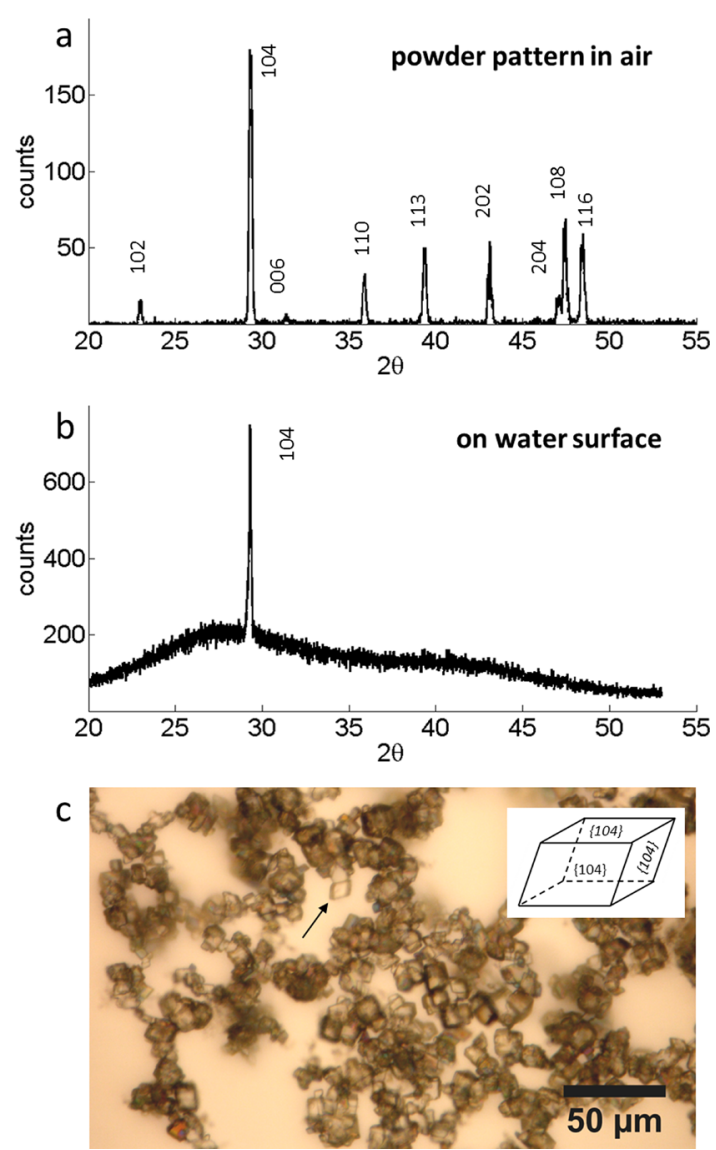

Figure 2. (a) $\theta-2 \theta$ diffraction pattern obtained from a $\mathrm{CaCO}_{3}$ powder pellet (in air). (b) Diffraction pattern of $\mathrm{CaCO}_{3}$ crystals at the airwater interface after aggregation of the crystals. (c) Micrograph of $\mathrm{CaCO}_{3}$ crystals floating at the air-water interface, after aggregation of the crystals. The arrow shows a crystal with a typical rhombohedral morphology, having its \{104] plane parallel to the interface. Inset: calcite rhombohedron habit, composed of six $\{104\}$ faces.

would be obtained for a monocrystalline calcite crystal cleaved along the $\{104\}$ plane. Microscopy images of the crystals (Figure 2c) clearly show some rhombohedra lying flat on their $\{104\}$ face, but the extent of the orientation effect (Figure 2b) could not have been inferred from the mere visual inspection of the crystals at the interface.

The crystal films we form from an aerosol are thin, and $\{104\}$ is the most conspicuous and energetically stable face of calcite. The crystal habit of calcite is to form rhombohedra with six external $\{104\}$ faces (Figure $2 c$ inset). It is conceivable that the observed orientation could simply result from the fact that rhombohedra tend to rest with their most expressed $\{104\}$ facet parallel to the substrate surface instead of being jammed in random positions as in a compact powder. To examine this possibility, we measured the XRD patterns of calcite particles that settled on a solid (glass) substrate (Figure 3a).
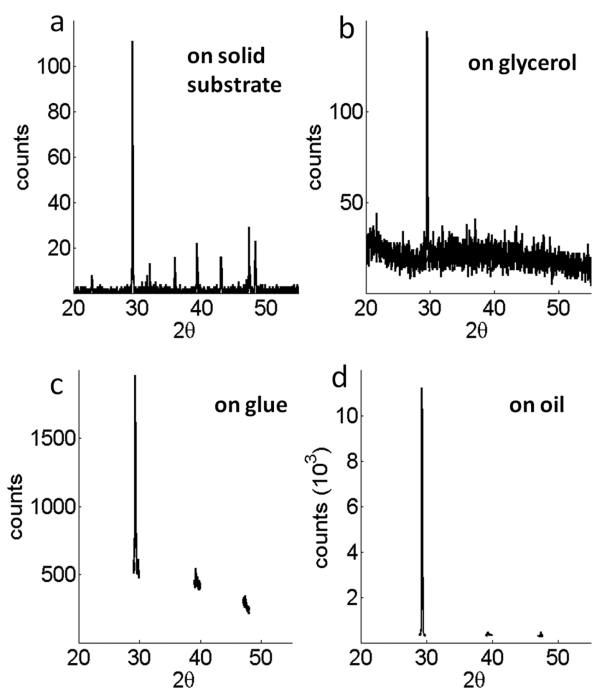

Figure 3. Diffraction pattern $30 \mathrm{~min}$ after forming a thin film of powder by settling of particles on (a) a solid glass substrate, (b) glycerol, (c) a $\sim 1 \mathrm{~mm}$ thick layer of viscous glue, and (d) oil. In panels $\mathrm{c}$ and $\mathrm{d}$, we performed the $2 \theta$ scan only in the vicinity of the three most intense peaks $(104,113$, and 108) of the powder diffraction pattern.

All of the diffraction peaks could be readily distinguished when the crystals settled at a solid interface (Figure 3a), unlike what we observed at a liquid interface. The relative intensities of some of the peaks of these thin calcite layers were changed compared with a bulk powder pellet (Figure 2a), indicating some degree of orientation. For example, for the diffraction pattern shown in Figure 3a, we found $I_{113} / I_{104}=0.2$, whereas this relative intensity for a bulk powder (Figure 2a) is 0.27 (consistent with Mincryst ${ }^{17}$ data, which indicates a theoretical peak intensity ratio of 0.278 ). The orientation effect on a solid substrate is, however, clearly much less pronounced that the one observed on a liquid surface. We conclude that the fact that the interface is liquid plays a key role in driving the orientation of the crystallites once they have settled at the air-liquid interface. More precisely, orientation could be due to (1) the increased in-plane mobility of the particles at a liquid interface or (2) surface tension, which could reorient crystals at the interface. We challenged hypothesis (1) by dispersing the particles on very viscous liquids, glycerol $(\eta=1.4 \mathrm{~Pa} \cdot \mathrm{s})$ or a thin $(\sim 1 \mathrm{~mm}$ ) layer of very viscous glue (Uhu, $\eta=10-100 \mathrm{~Pa}$. s). Lateral mobility was considerably reduced on glycerol as, after 1 day, the particles gathered in 10-30 small clusters but the clusters remained well separated because of their low mobility. On glue motility was abolished; we did not observe any aggregate formation. On both glycerol and glue, we found complete $<104>$ orientation (Figure $3 b, c$ ) just $30 \mathrm{~min}$ after the particles were deposited at the interface. We therefore conclude 
that the surface tension of the liquid drives the orientation of the crystals at the interface. We also observed that for some samples, on water and glycerol, other peaks $(113,108,116)$ could sometimes be distinguished, indicating a less marked $<104>$ orientation (Figure S1). This variability might be due to the fact that upon settling at the interface, and depending on the density of crystals in the aerosol, some crystals come to sit on top of other crystals, forming multilayers. Crystals in such multilayers might not be in contact with the liquid and would therefore not be oriented by surface tension. We also investigated the effects of changing the polarity of the liquid by dispersing the particles on silicone oil. Complete <104> orientation of the particles at the interface could be obtained on oil as well (Figure 3d).

We examined whether we could capture the dynamics of crystal orientation by taking XRD spectra at $5 \mathrm{~min}$ time intervals (time required for a scan). We found that the XRD spectra did not vary in time for all liquids used (water, glycerol, glue); that is, the orientation of the crystallites took place within at most $5 \mathrm{~min}$ after settling of the crystals at the liquid interface. In particular, orientation of the crystals occurred well before they had assembled to form visible aggregates (on water and glycerol).

We further questioned whether the surface-tension driven orientation effect was specific to calcite or could be observed using other crystals. We used fluorite $\left(\mathrm{CaF}_{2}\right)$, which has a simple cubic crystal structure and is almost insoluble. We found that settling of the $\mathrm{CaF}_{2}$ particles at the air-water interface led to an extinguishing of all peaks except 111 (Figure 4a,b). The
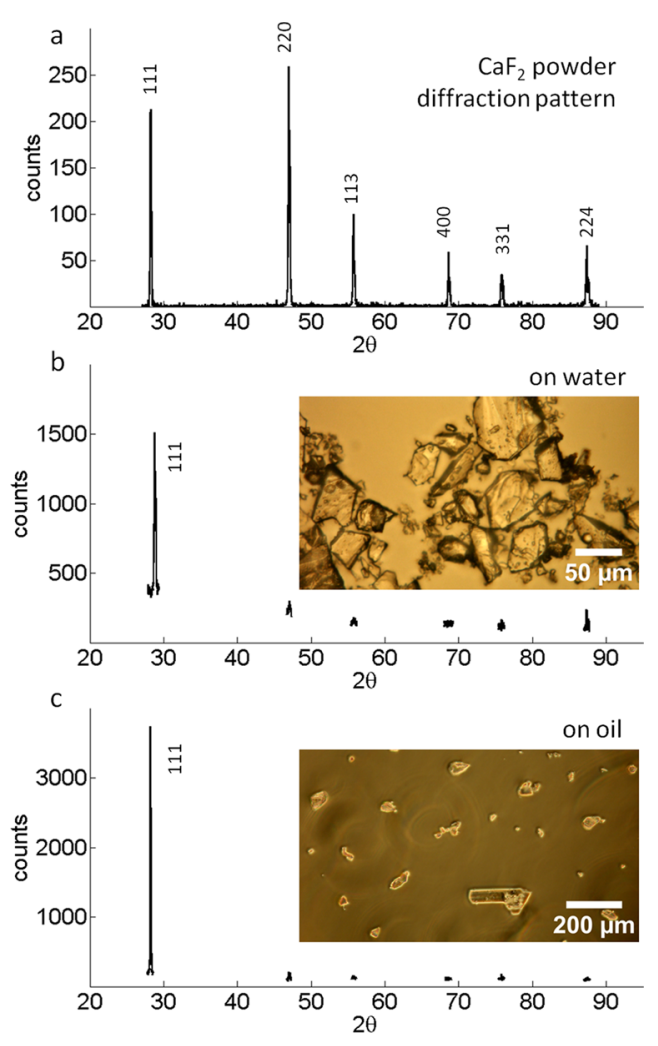

Figure 4. (a) $\theta-2 \theta$ diffraction pattern obtained from a $\mathrm{CaF}_{2}$ powder pellet (in air). Diffraction pattern of $\mathrm{CaF}_{2}$ crystals dispersed (b) at the air-water interface and (c) at the air-oil interface. $2 \theta$ scans in panels $\mathrm{b}$ and $\mathrm{c}$ have been performed in the vicinity of the six peaks found in panel a. Insets: micrographs of the crystals at the liquid interface. same orientation effect occurred at the air-oil interface (Figure $4 c)$. Similarly to $\{104\}$ for calcite, $\{111\}$ is the most stable and widely expressed plane of $\mathrm{CaF}_{2}$. The $\mathrm{CaF}_{2}$ crystals were bigger $(5-50 \mu \mathrm{m})$ than the $\mathrm{CaCO}_{3}$ crystals, and they have a simple, plate-like morphology. We found that the platelets lie flat, on their $\{111\}$ face, on the liquid interface (insets of Figure $4 b, c$ ). This was especially clear at the oil interface, where crystals were well separated from each other (Figure 4c). The separation between the $\mathrm{CaF}_{2}$ crystals dispersed on oil very likely results from electrical repulsion, possibly due to charge transfer with the keratine of the brush hair; the day after, we found that the crystals had aggregated, most likely because the electrical charge had dissipated.

An important question is whether this capillary orientation effect can be used to form oriented crystalline films on solid substrates. To this end we dispersed $\mathrm{CaCO}_{3}$ crystals on a film of ethanol spread on a piece of glass (Figure 5 inset). The

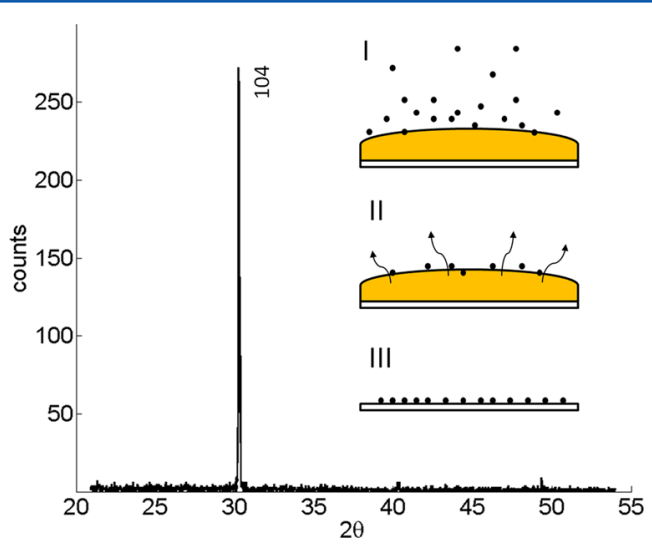

Figure 5. Oriented thin-film fabrication procedure. Step I: Crystallites are dispersed on a film of ethanol on a glass slide. Step II: The crystals are oriented by surface tension and the ethanol evaporates. Step III: The glass slide is coated with a thin film of oriented crystallites. The $\theta$ $2 \theta$ diffraction of the resulting dry mineral coating (step III) is shown.

crystals dispersed on ethanol undergo a vivid motion (Figure S2) because quick evaporation of the ethanol cools the surface, driving convection currents from the bottom of the container and at the surface of the liquid. ${ }^{18}$ As a result, on ethanol the crystals quickly aggregate to form one dense (not fractal) layer. We then let the ethanol evaporate and measured the $\theta-2 \theta$ XRD diffraction pattern of the dry, compact crystal layer deposited on a glass substrate. We found that the $<104>$ orientation of the crystals was conserved (Figure 5) after drying; the resulting thin films feature properties similar to those of mesocrystals. ${ }^{19}$

The experiments we conducted lead us to suggest a simple mechanism of how crystals orient at an air-liquid interface. Most minerals are characterized by a few low-energy cleavage planes, which make up most of the surface area of the ground powder. For calcite and fluorite, these are, respectively, $\{104\}$ and $\{111\}$. When a mineral particle lands on the liquid interface, capillary forces exert a torque that tends to reorient the crystallite so that the cleavage plane lies parallel to the airliquid interface (Figure 6).

The characteristic time for reorientation is obtained by equating viscous and capillary torques, yielding $\tau=\eta a / \gamma$, where $\eta$ is the dynamic viscosity of the liquid, $\gamma$ is its surface tension, and $a$ is the size of the crystal (see the Supporting Information for details on the derivation of this relation). For water $(\gamma=72$ $\left.\mathrm{mN} / \mathrm{m}, \eta=10^{-3} \mathrm{~Pa} \cdot \mathrm{s}\right)$, we find $\tau$ on the order of 0.1 to $1 \mu \mathrm{s}$. 


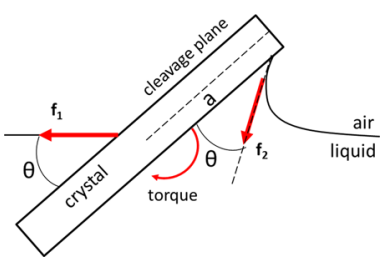

Figure 6. Scheme of the forces $\left(f_{1}, f_{2}\right)$ and of the resulting torque exerted by meniscus forces on an initially randomly oriented crystal at the air-water interface. $\theta$ : contact angle of the liquid with the crystal; a: crystal size.

For glycerol and glue, $\tau$ is, respectively, 0.1 to $1 \mathrm{~ms}$ and $10-100$ ms. This shows that even on the most viscous liquid (glue) reorientation occurs within less than a second. This explains why we were not able to resolve the orientation dynamics using our setup. The orientation of crystals occurred over a wide range of surface tension as oriented films could be obtained on ethanol $(\gamma=22 \mathrm{mN} / \mathrm{m})$, oil $(\gamma=15-22 \mathrm{mN} / \mathrm{m})$, and water $(\gamma$ $=72 \mathrm{mN} / \mathrm{m})$.

We demonstrated that orientation of a thin film of crystallites on a solid substrate could be achieved by depositing the particles on a volatile liquid and letting the latter evaporate. This simple procedure could be integrated to other ceramics manufacturing processes such as sintering of the oriented particles, addition of an organic component, and multilayering for the fabrication of nacre mimics ${ }^{20}$ or surface-mineralized implants. ${ }^{21}$ The oriented particle films could also be used as templates for further oriented crystal overgrowth or for contactangle measurement of sessile drops on well-defined crystallographic planes. Knowing and controlling the orientation of the particles at the air-water interface is also important to understand the self-assembly behavior of submicron particles at an interface, which is governed by competing capillary, dielectric, electric, or magnetic interactions between the particles. $^{22-24}$ Our work finally demonstrates that surface tension alone is sufficient to orient crystals along a particular crystallographic axis: This should be critically assessed when studying the capacity of amphiphiles to direct crystal growth at the air-water interface. ${ }^{15}$

\section{EXPERIMENTAL METHODS}

Calcite powder $\left(\mathrm{CaCO}_{3}\right.$, Sigma $)$ was dispensed in a dish and collected with a brush. The brush was struck a few times above a Petri dish filled with liquid (distilled water, silicone oil, glycerol, or ethanol). The cloud of particles (aerosol) settled on the liquid interface. The same procedure was subsequently repeated with $\mathrm{CaF}_{2}$ (ground from a geological source). We then put the Petri dish on the XRD (Siemens D5000) sample holder and adjusted the $z$-position so that the liquid interface was at the center of the circle formed by the rotating X-ray source and detector arms. Crystal orientations at the liquid interface or on a solid substrate were determined by X-ray diffraction (Siemens D5000) in $\theta-2 \theta$ mode. In this mode, only crystallographic planes that are parallel to the substrate surface are detected. At least three replicate scans were obtained for each liquid-crystal pair. We used an angular step $\Delta \theta=0.01^{\circ}$. To accelerate data acquisition, some scans (Figures 3 and 4 ) were performed only in the vicinity of the three (six) most intense diffraction peaks of $\mathrm{CaCO}_{3}\left(\mathrm{CaF}_{2}\right)$. Crystals at the interface were additionally imaged by optical or phase contrast microscopy (Leica). The surface concentration of crystals was $\sim 10 \%$; this was deduced by measuring the surface area occupied by white aggregates (Figure 1, right, low magnification) on a dark background, on the next day, after aggregation had occurred.

\section{ASSOCIATED CONTENT}

Supporting Information

The Supporting Information is available free of charge on the ACS Publications website at DOI: 10.1021/acs.jpclett.6b01312.

Figure S1: XRD scans on water and glycerol showing incomplete 104 orientation. Figure S2: dynamics of $\mathrm{CaCO}_{3}$ particles on ethanol; derivation of formula for reorientation time. (PDF)

\section{AUTHOR INFORMATION}

\section{Corresponding Author}

*E-mail: nicolas.chevalier@univ-paris-diderot.fr.

\section{Present Address}

${ }^{\dagger}$ N.R.C.: Laboratoire Matière et Systèmes Complexes, Université Paris Diderot/CNRS UMR 7057, 10 rue Alice Domon et Léonie Duquet, 75013 Paris, France.

\section{Notes}

The authors declare no competing financial interest.

\section{ACKNOWLEDGMENTS}

We acknowledge funding by Triangle de la Physique and wish to thank Corinne Chevallard for a critical reading of the manuscript and Pascale Jégou and Christian Blot for technical help.

\section{REFERENCES}

(1) Taylor, M. P.; Drysdale, R. N.; Carthew, K. D. The Formation and Environmental Significance of Calcite Rafts in Tropical TufaDepositing Rivers of Northern Australia. Sedimentology 2004, 51, 1089-1101.

(2) Kuzmenko, I.; Rapaport, H.; Kjaer, K.; Als-Nielsen, J.; Weissbuch, I.; Lahav, M.; Leiserowitz, L. Design and Characterization of Crystalline Thin Film Architectures at the Air-Liquid Interface: Simplicity to Complexity. Chem. Rev. 2001, 101, 1659-1696.

(3) Meldrum, F. C.; Cölfen, H. Controlling Mineral Morphologies and Structures in Biological and Synthetic Systems. Chem. Rev. 2008, 108, 4332-4432.

(4) Popovitzbiro, R.; Wang, J. L.; Majewski, J.; Shavit, E.; Leiserowitz, L.; Lahav, M. Induced Freezing of Supercooled Water into Ice by SelfAssembled Crystalline Monolayers of Amphiphilic Alcohols at the AirWater-Interface. J. Am. Chem. Soc. 1994, 116, 1179-1191.

(5) Wang, F.; Seo, J.-H.; Luo, G.; Starr, M. B.; Li, Z.; Geng, D.; Yin, X.; Wang, S.; Fraser, D. G.; Morgan, D.; et al. Nanometre-Thick Single-Crystalline Nanosheets Grown at the Water-air Interface. Nat. Commun. 2016, 7, 10444.

(6) Kewalramani, S.; Kim, K.; Stripe, B.; Evmenenko, G.; Dommett, G. H. B.; Dutta, P. Observation of an Organic-Inorganic Lattice Match during Biomimetic Growth of (001)-Oriented Calcite Crystals under Floating Sulfate Monolayers. Langmuir 2008, 24, 10579-10582.

(7) Chevalier, N. R.; Chevallard, C.; Goldmann, M.; Brezesinski, G.; Guenoun, P. $\mathrm{CaCO}_{3}$ Mineralization under $\beta$-Sheet Forming Peptide Monolayers. Cryst. Growth Des. 2012, 12, 2299-2305.

(8) Di Felice, R.; Corni, S. Simulation of Peptide - Surface Recognition. J. Phys. Chem. Lett. 2011, 2, 1510-1519.

(9) Lee, J. R. I.; Han, T. Y. J.; Willey, T. M.; Nielsen, M. H.; Klivansky, L. M.; Liu, Y.; Chung, S.; Terminello, L. J.; Van Buuren, T.; De Yoreo, J. J. Cooperative Reorganization of Mineral and Template during Directed Nucleation of Calcium Carbonate. J. Phys. Chem. C 2013, 117, 11076-11085.

(10) DiMasi, E.; Gower, L. Biomineralization Sourcebook: Characterization of Biominerals and Biomimetic Materials; CRC Press, 2014. 
(11) Chevalier, N. R. Do Surface Wetting Properties Affect Calcium Carbonate Heterogeneous Nucleation and Adhesion? J. Phys. Chem. C 2014, 118, 17600-17607.

(12) Parikh, H.; De Guire, M. R. Recent Progress in the Synthesis of Oxide Films from Liquid Solutions. J. Ceram. Soc. Jpn. 2009, 117, 228235.

(13) Stripe, B.; Uysal, A.; Lin, B.; Meron, M.; Dutta, P. Charge, Stereochemistry, or Epitaxy? Toward Controlled Biomimetic Nucleation at Mixed Monolayer Templates. Langmuir 2012, 28, 572-578.

(14) Fricke, M.; Volkmer, D. Crystallization of Calcium Carbonate beneath Insoluble Monolayers: Suitable Models of Mineral-Matrix Interactions in Biomineralization? Topics in Current Chemistry. 2007, $270,1-41$.

(15) DiMasi, E.; Olszta, M. J.; Patel, V. M.; Gower, L. B. When Is Template Directed Mineralization Really Template Directed? CrystEngComm 2003, 5, 346.

(16) Nakayama, T.; Nakahara, A.; Matsushita, M. Cluster-Cluster Aggregation of Calcium Carbonate Colloid Particles at the Air/Water Interfacee. J. Phys. Soc. Jpn. 1995, 64, 1114-1119.

(17) WWW-MINCRYST. http://database.iem.ac.ru/mincryst/index. php.

(18) Zhang, N.; Chao, D. F. Mechanisms of Convection Instability in Thin Liquid Layers Induced by Evaporation. Int. Commun. Heat Mass Transfer 1999, 26, 1069-1080.

(19) Zhou, L.; O’Brien, P. Mesocrystals - Properties and Applications. J. Phys. Chem. Lett. 2012, 3, 620-628.

(20) Corni, I.; Harvey, T. J.; Wharton, J. a; Stokes, K. R.; Walsh, F. C.; Wood, R. J. K. A Review of Experimental Techniques to Produce a Nacre-like Structure. Bioinspiration Biomimetics 2012, 7, 031001.

(21) Yeo, I.-S. Reality of Dental Implant Surface Modification: A Short Literature Review. Open Biomed. Eng. J. 2014, 8, 114-119.

(22) Morgan, A. R.; Ballard, N.; Rochford, L. a.; Nurumbetov, G.; Skelhon, T. F.; Bon, S. a. F. Understanding the Multiple Orientations of Isolated Superellipsoidal Hematite Particles at the Oil-water Interface. Soft Matter 2013, 9, 487.

(23) Chatterjee, N.; Flury, M. Effect of Particle Shape on Capillary Forces Acting on Particles at the Air-Water Interface. Langmuir 2013, 29, 7903-7911.

(24) Wickman, H. H.; Korley, J. N. Colloid Crystal Self-Organization and Dynamics at the Air/water Interface. Nature 1998, 393, 445-447. 